\title{
Antibacterial Activity of Phenyl Isothiocyanate on Escherichia coli and Staphylococcus aureus
}

\author{
Ana Cristina Abreu ${ }^{1}$, Anabela Borges ${ }^{1,2}$, Lúcia Chaves Simões ${ }^{1,3}$, Maria José Saavedra ${ }^{2}$ and Manuel \\ Simões $^{1 *}$ \\ ${ }^{1}$ LEPAE, Department of Chemical Engineering, Faculty of Engineering, University of Porto, Rua Dr. Roberto Frias, $s / n$, \\ 4200-465 Porto, Portugal \\ ${ }^{2}$ CECAV-Veterinary and Animal Science Research Center, Quality and Food Safety of Animal Products Group \\ University of Trás-os-Montes and Alto Douro, Apartado 1013, 5000-801 Vila Real, Portugal \\ ${ }^{3}$ IBB-Institute for Biotechnology and Bioengineering, Centre of Biological Engineering, University of Minho, Campus \\ de Gualtar 4710-057 Braga, Portugal
}

\begin{abstract}
The present study has been aimed to assess the antibacterial effects of the glucosinolate hydrolysis product phenyl isothiocyanate (PITC) against Escherichia coli and Staphylococcus aureus. Aspects on the antibacterial mode of action of PITC have also been characterized, such as the changes on surface physicochemical characteristics and membrane damage. The minimum inhibitory concentration of PITC was $1000 \mu \mathrm{g} / \mathrm{mL}$, for both bacteria. The antimicrobial potential of PITC was compared with selected antibiotics (ciprofloxacin, erythromycin, streptomycin, tetracycline and spectinomycin), that reported a moderate effect. The combination of PITC with ciprofloxacin and erythromycin against $S$. aureus exhibited a good antimicrobial efficacy, due to an additive effect (the diameter of inhibition zones increased from 30 to $40 \mathrm{~mm}$ for ciprofloxacin and almost the double for erythromycin). The other combinations reported unsatisfactory results against both bacteria. The study of the physiological changes induced by PITC action demonstrated the interaction between the electrophilic compound and the bacterial cells at several points that causes changes in membrane properties (decreases negative surface charge, increases surface hydrophilicity and electron donor characteristics). PITC was also found to disturb membrane function, as manifested by phenomena such as cellular disruption and loss of membrane integrity, triggering cell death.
\end{abstract}

Keywords: Antibiotic-chemical synergy, antimicrobial action, mechanisms of action, phenyl isothiocyanate.

\section{INTRODUCTION}

Antibiotics are one of the most successful chemotherapeutic agents in history due to their extreme efficiency in early recognition and treatment of infections, previously untreatable and fatal $[1,2]$. However, as the access to antibiotics has become quite feasible they are being used to treat even the most common infection [1]. These treatments are commonly performed not only in humans, but also in animals and agriculture sometimes in inadequate doses and over any time period. This practice allows the spread of resistant bacteria [3].

The increasing of bacterial resistance to antimicrobials has now emerged as a global threat that poses enormous health hazards, such as the increased frequency of treatment failures and severity of infections $[4,5]$. This situation demands the moderation of antibiotic use in the community and both the prescriber and the consumer must be made aware of this reality $[4,6]$. Moreover, substantial resources have been invested in the research of new antimicrobial compounds, mainly of microbial and plant origin $[7,8]$. According to the report of World Health Organization, plants

*Address correspondence to this author at the LEPAE, Department of Chemical Engineering, Faculty of Engineering, University of Porto, Rua Dr. Roberto Frias, s/n, 4200-465 Porto, Portugal; Tel: 00351225081654; Fax: 00351225081449; E-mail: mvs@fe.up.pt are the best source of products highly rich with antimicrobial properties [4]. Additionally, since there are approximately 250,000 species of such plants and most of them have not yet been examined [9], the prospects of finding new therapeutic compounds seem promising. The curative potentials and efficacy of these medicinal plants are well documented and considerable amount of work have been published [4, 8-12].

Glucosinolates are a class of organic compounds that contain sulfur and nitrogen and are extracted from glucose and amino acid. They occur as secondary metabolites of almost all plants of the order Brassicales (including the families Brassicaceae, Capparidaceae and Caricaceae) [13], which include common vegetables such as cabbage, broccoli, cauliflower, brussels sprouts, kohlrabi and kale [14]. The antibacterial activity of glucosinolates has been recognized for many decades $[10,15,16]$. These compounds, which are present in the cell vacuole, are known to play roles in cell defense and signaling, being converted to isothiocyanates (ITCs), thiocyanates, nitriles or oxazolidinethiones by an endogenous myrosinase (thioglucoside glucohydrolase EC 3.2.3.1) upon wounding of the plant [16-20]. Glucosinolates possess limited biological activity but some studies already demonstrated the broad biocidal activity of glucosinolate hydrolysis products (GHP) [21]. ITCs are known as the most common and predominant GHP and as major inhibitors of 
microbial activity [20]. Most ITCs are electrophiles due to the presence of a $-\mathrm{N}=\mathrm{C}=\mathrm{S}$ group [22, 23]. This group is likely to react with various nucleophilic compounds, especially those that are S-based (thiocarbamoylation), but also with $-\mathrm{NH}_{2}$ and $-\mathrm{OH}$ groups [23, 24].

In the present study, phenyl isothiocyanate (PITC) was tested against two clinically significant bacteria: Escherichia coli and Staphylococcus aureus. The antimicrobial activity of PITC and its ability to act synergistically with selected antibiotics to control bacterial growth were investigated. Also, the physiological changes induced by PITC action on bacterial cells were determined.

\section{MATERIALS AND METHODS}

\section{Bacterial Strains}

Bacteria used in this study were Escherichia coli CECT 434 and Staphylococcus aureus CECT 976. Mueller-Hinton broth (Merck, Portugal) was used to culture both bacteria, at $37^{\circ} \mathrm{C}$. These bacteria have been used as model microorganisms for antimicrobial tests with phytochemical products [8, 20].

\section{Phenyl Isothiocyanate and Antibiotics}

PITC (Fig. 1; Sigma, Portugal) was prepared in dimethyl sulfoxide (DMSO; Sigma). Ciprofloxacin (CIP), erythromycin (ERY), streptomycin (STR), tetracycline (TET) and spectinomycin (SPT) were obtained from Sigma (Portugal). The antibiotics used were according to the Clinical and Laboratory Standards Institute (CLSI)/NCCLS guidelines [25]: CIP - $5 \mu \mathrm{g} / \mathrm{disc}$; ERY - $15 \mu \mathrm{g} / \mathrm{disc}$; STR - $30 \mu \mathrm{g} / \mathrm{disc}$; TET $-30 \mu \mathrm{g} /$ disc; and SPT $-100 \mu \mathrm{g} /$ disc.

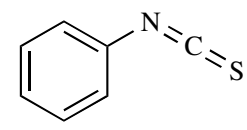

Fig. (1). Chemical structure of PITC.

\section{Minimum Inhibitory Concentration Determination}

To determine whether the presence of PITC affects the bacterial growth in a liquid culture, the minimal inhibitory concentration (MIC) was determined using the standard CLSI/NCCLS broth microdilution method [25]. MIC is defined as the lowest concentration of the antimicrobial product that inhibits bacterial growth under laboratory conditions. The experiments were repeated at three different intervals.

\section{Disc Diffusion Assay}

The bacteria were obtained from overnight cultures in Mueller-Hinton agar (Merck, Germany). Antibacterial activity was tested using a modification of the disc diffusion method originally described by Bauer et al. [26]. The suspensions were prepared in sterile saline solution $(0.9 \%)$ by adjusting the turbidity as to match $0.5 \mathrm{McFarland}$ standards. The bacteria suspensions were vortexed (Heidolph, model Reax top - 50\% of maximum power input) and seeded over hardened Mueller-Hinton agar (1.0\% w/v; Oxoid, England) Petri dishes (90 mm diameter) using a sterilized cotton swab.
Sterile filter paper discs (6 mm diameter; Oxoid) impregnated with $15 \mu \mathrm{L}$ of PITC (at MIC) were placed on the agar plate seeded with the respective bacteria. The plates were incubated at $37{ }^{\circ} \mathrm{C}$ for 24 hours. Discs of antibiotics were used as positive controls and discs impregnated with DMSO were used as negative controls. After incubation, the diameter in $\mathrm{mm}$ of the inhibition halos or clear zones around the discs was recorded. All tests were performed in triplicate and the antibacterial activity was expressed as the mean of inhibition diameter.

\section{Antibiotic-PITC Dual Combination}

Bacteria obtained from an overnight growth cultures (log phase cultures) were suspended in $0.5 \mathrm{~mL}$ of saline solution $(0.9 \%)$ and mixed with $5 \mathrm{~mL}(0.7 \% \mathrm{w} / \mathrm{v})$ of Mueller-Hinton agar at $45^{\circ} \mathrm{C}$ [27]. PITC dissolved in DMSO was added to the cell/Mueller-Hinton agar mixture yielding a final concentration corresponding to the MIC. The final cell concentration was reported as approximately $0.5 \mathrm{McFarland}$ standards. The vortexed mixtures were poured over hardened MuellerHinton agar $(1.0 \% \mathrm{w} / \mathrm{v})$ plates using a sterilized cotton swab and allowed to set. Antibiotic discs were placed on the surface of plates containing the PITC and bacteria [8]. After an incubation of 24 hours at $37^{\circ} \mathrm{C}$, growth inhibition zones were measured according to CLSI/NCCLS [25]. All tests were performed in triplicate and the antibacterial activity was expressed as the mean of inhibition diameter.

\section{Antibacterial Activity Classification}

The antibacterial effects of PITC were classified according to the scheme proposed by Aires et al. [28]: noneffective (-) - inhibition halo $=0$; moderate efficacy $(+)-0<$ inhibition halo $<$ antibiotic inhibition halo; good efficacy $(++)$ - antibiotic inhibition halo $<$ inhibition halo $<2 \times$ antibiotic inhibition halo; strong efficacy $(+++)$ - inhibition halo $>2 \times$ antibiotic inhibition halo.

The effect of dual combinations of antibiotics and phytochemicals was classified according to Saavedra et al. [20]: antagonism (-) - if [inhibition halo - (antibiotic inhibition halo + PITC inhibition halo)/2] $<0$; indifference $(+)-$ if $0 \leq$ [inhibition halo - (antibiotic inhibition halo + PITC inhibition halo)/2] $<$ antibiotic inhibition halo or PITC inhibition halo; additive $(++)$ - if antibiotic inhibition halo $<$ [inhibition halo - (antibiotic inhibition halo + PITC inhibition halo) $/ 2]<$ $2 \times$ antibiotic inhibition halo or PITC inhibition halo; synergy $(+++)$ - if inhibition halo $>3 \times$ antibiotic inhibition halo or PITC inhibition halo. The classification was made to determine the highest inhibition halos caused by the antibiotic or PITC application for each condition tested.

\section{Determination of Zeta Potential of Bacteria}

Zeta potential experiments were performed according to Simões et al. [29]. Overnight grown cultures of E. coli and $S$. aureus were centrifuged at $3999 \mathrm{~g}$ for $10 \mathrm{~min}$ and then washed twice with sterile water. Cell suspensions were incubated with PITC (at MIC and $5 \times$ MIC) for 1 hour at $37^{\circ} \mathrm{C}$. Samples without PITC were used as control. The zeta poten- 
tial experiments were performed using a Malvern Zetasizer instrument (Nano Zetasizer, Malvern instruments, UK) [30]. All experiments were performed in triplicate and were repeated at three different occasions.

\section{Physico-chemical Characterization of Bacterial Surface}

The physico-chemical properties of the bacterial surface were determined using the sessile drop contact angle method on bacterial lawns [31]. Samples with PITC (at MIC and $5 \times$ MIC) were incubated for 1 hour. Determination of contact angles was performed automatically using a model OCA 15 Plus (DataPhysics, Germany) video based optical contact angle measuring instrument, allowing image acquisition and data analysis. Hydrophobicity was evaluated after contact angles measurements, following the van Oss approach [3234]. The degree of hydrophobicity of a given surface (s) is expressed as the free energy of interaction between two entities of that surface, when immersed in water (w) $-\Delta \mathrm{G}_{\text {sws }}$ $\left(\mathrm{mJ} / \mathrm{m}^{2}\right)$. When $\Delta \mathrm{G}_{\mathrm{sws}}<0$, the interaction between the two entities is stronger than the interaction of each entity with water and the material is considered hydrophobic. Conversely, if $\Delta \mathrm{G}_{\mathrm{sws}}>0$, the material is hydrophilic. $\Delta \mathrm{G}_{\mathrm{sws}}$ can be calculated through the surface tension components of the interacting entities, according to:

$$
\Delta \mathrm{G}_{\mathrm{sws}}=-2\left(\sqrt{\gamma_{\mathrm{s}}^{\mathrm{LW}}}-\sqrt{\gamma_{\mathrm{w}}^{\mathrm{LW}}}\right)^{2}+4\left(\sqrt{\gamma_{\mathrm{s}}^{+} \gamma_{\mathrm{w}}^{-}}+\sqrt{\gamma_{\mathrm{s}}^{-} \gamma_{\mathrm{w}}^{+}}-\sqrt{\gamma_{\mathrm{s}}^{+} \gamma_{\mathrm{s}}^{-}}-\sqrt{\gamma_{\mathrm{w}}^{+} \gamma_{\mathrm{w}}^{-}}\right)
$$

Where, $\gamma^{L W}$ accounts for the Lifshitz-van der Waals component of the surface free energy, and $\gamma^{+}$and $\gamma^{-}$are the electron acceptor and electron donor parameters of the Lewis acid-base component $\left(\gamma^{\mathrm{AB}}\right)$, respectively, as $\gamma^{\mathrm{AB}}=\sqrt{\gamma^{+} \gamma^{-}}$. The measurements were carried out at room temperature $\left(23{ }^{\circ} \mathrm{C} \pm 2\right)$ using three different liquids: water, the polar formamide and the apolar $\alpha$-bromonaphtalene (Sigma, Portugal). The liquids surface tension components were obtained from literature [35]. Once the values are obtained, three equations of the type below can be solved:

$$
(1+\cos \theta) \gamma_{1}^{\mathrm{Tot}}=2\left(\sqrt{\gamma_{\mathrm{s}}^{\mathrm{LW}} \gamma_{\mathrm{w}}^{\mathrm{LW}}}+\sqrt{\gamma_{\mathrm{s}}^{+} \gamma_{\mathrm{w}}^{-}}+\sqrt{\gamma_{\mathrm{s}}^{-} \gamma_{\mathrm{w}}^{+}}\right)
$$

Where, $\theta$ is the contact angle and $\gamma^{\mathrm{TOT}}=\gamma^{\mathrm{LW}}+\gamma^{\mathrm{AB}}$. Measurements of the contact angle were performed at least with 20 determinations for each liquid and for each microorganism at three independent experiments.

\section{Assessment of Membrane Integrity - Propidium Iodide Uptake}

The Live/Dead BacLight ${ }^{\mathrm{TM}}$ kit (Invitrogen) is considered as a quick method for estimating both viable and total counts of bacteria [30]. The kit consists of two stains, propidium iodide (PI) and SYTO $9^{\mathrm{TM}}$, which both stain nucleic acids. Green fluorescing SYTO $9^{\mathrm{TM}}$ is able to enter all cells and is used for assessing total cell counts, whereas red fluorescing PI enters only those cells with damaged cytoplasmic membrane. The combination of these two stains generates red fluorescing cells [36]. Overnight grown cultures of E. coli and $S$. aureus were centrifuged and washed twice with $0.9 \%$ saline solution as described by Simões et al. [8]. The suspensions $\left(1 \times 10^{8}\right.$ cells $\left./ \mathrm{mL}\right)$ were incubated with PITC (at MIC and $5 \times$ MIC) for 1 hour. Controls with bacteria non-exposed to PITC were used. After PITC exposure, bacteria were transferred to saline solution and diluted 1:10. Three hundred microliters of each diluted suspension were filtered through a Nucleopore ${ }^{\circledR}$ (Whatman) black polycarbonate membrane (pore size $0.22 \mu \mathrm{m}$ ) and stained with SYTO $9^{\mathrm{TM}}$ and PI according to the instructions provided by the manufacturer. The microscope used to observe stained bacteria was a LEICA DMLB2 with a mercury lamp HBO/100W/3 incorporating a CCD camera to acquire images using IM50 software (LEICA) and a $100 \times$ oil immersion fluorescence objective. The optical filter combination for optimal viewing of stained mounts consisted of a 480 to $500 \mathrm{~nm}$ excitation filter in combination with a $485 \mathrm{~nm}$ emission filter (Chroma 61000-V2 DAPI/FITC/TRITC). Three independent experiments were performed for testing each condition.

\section{Statistical Analysis}

The data was analyzed using One-Way ANOVA using the statistical program SPSS 17.0. The results were presented as the means \pm SEM (standard error of the mean). Statistical calculations were based on confidence level equal or higher than $95 \%(P<0.05$ was considered statistically significant).

\section{RESULTS AND DISCUSSION}

The development of antibiotic resistance by some pathogenic bacteria has been a serious global problem, giving rise to multi-resistant strains wherein treatment is longer and frequently ineffective. Therefore, there is a constant need of discovering new antimicrobial products. Plants produce a huge number of phytochemicals with antimicrobial activity and a major part of this chemical diversity is related to defense/stress mechanisms against a broad array of microorganisms, insects, nematodes and even other plants [37]. Phytochemicals may inhibit bacterial growth through different mechanisms than the presently used antibiotics, providing an interesting approach to drug-resistant infections.

Phytochemicals are generally classified as antimicrobials on the basis of susceptibility tests that produce inhibitory concentrations ranging from 100 to $1000 \mu \mathrm{g} / \mathrm{mL}$ [38]. In this study, the MIC of PITC was $1000 \mu \mathrm{g} / \mathrm{mL}$ for both bacteria. $E$. coli and $S$. aureus are the most clinically significant bacteria due to their ability to develop resistance to multiple and conventional antibiotics [8]. The MIC values of $1000 \mu \mathrm{g} / \mathrm{mL}$ for PITC can be very high for a clinical application.

The antimicrobial activity of PITC was also evaluated by the disc diffusion assay using PITC alone and in combination (Table 1) with five selected antibiotics (two aminoglycosides - STR and SPT, one quinolone - CIP, one macrolide - ERY and one polyketide - TET). According to the CLSI/NCCLS guidelines [25], the strains are considered susceptible to all antibiotics. CIP and TET exhibited high efficacy against $E$. coli and $S$. aureus strains while ERY and SPT $(P<0.05)$ were found to be less effective. The negative control with DMSO did not report any growth inhibitory effects. PITC also demonstrated weak antibacterial activity 
Table 1. Antibacterial Activity Against $E$. coli and $S$. aureus Observed by Disc Diffusion Assay with Single and Antibiotic-PITC (at MIC) Dual Combinations (the mean \pm SEM of at Least Three Replicates are Illustrated). Classification of the Antimicrobial Potential of Dual Combinations: Antagonism (-); indifference (+); additive (++); synergy (+++). CIP - ciprofloxacin, ERY - erythromycin, STR - streptomycin, TET - tetracycline, SPT - spectinomycin, PITC - phenyl isothiocyanate

\begin{tabular}{|c|c|c|c|c|c|c|}
\hline & \multicolumn{3}{|c|}{ E. coli } & \multicolumn{3}{|c|}{ S. aureus } \\
\hline & \multicolumn{2}{|c|}{ Diameter of Inhibition Zone (mm) } & \multirow{2}{*}{$\begin{array}{c}\text { Classification Relative to } \\
\text { Antibiotic }\end{array}$} & \multicolumn{2}{|c|}{ Diameter of Inhibition Zone (mm) } & \multirow{2}{*}{$\begin{array}{c}\text { Classification Relative to } \\
\text { Antibiotic }\end{array}$} \\
\hline & Single & Antibiotic-PITC & & Single & Antibiotic-PITC & \\
\hline ERY & $16.0 \pm 1.0$ & $19.3 \pm 1.2$ & + & $23.5 \pm 1.5$ & $45.0 \pm 1.2$ & ++ \\
\hline CIP & $39.3 \pm 1.2$ & $52.3 \pm 2.1$ & + & $30.0 \pm 2.7$ & $48.0 \pm 2.8$ & ++ \\
\hline SPT & $25.7 \pm 0.6$ & $27.7 \pm 1.5$ & + & $12.0 \pm 1.0$ & $16.7 \pm 0.6$ & + \\
\hline STR & $28.3 \pm 1.5$ & $22.0 \pm 1.7$ & + & $21.5 \pm 2.1$ & $21.0 \pm 1.0$ & + \\
\hline TET & $27.7 \pm 1.2$ & $34.7 \pm 0.6$ & + & $43.0 \pm 1.0$ & $45.7 \pm 1.5$ & + \\
\hline PITC & $13.7 \pm 0.6$ & n.a. & n.a. & $9.67 \pm 0.6$ & n.a. & n.a. \\
\hline
\end{tabular}

n.a. - not applicable

against the bacteria tested (Table $\mathbf{1}$ ). The antibacterial activity of PITC was considered moderate $(+)$ when compared with the antibiotics. PITC showed higher activity against $E$. coli compared to $S$. aureus $(P<0.05)$. This fact was not expected since Gram-negative bacteria are generally less susceptible to antimicrobials acting on multiple biochemical targets of the cell compared to those Gram-positive. The outer membrane and a set of multi-drug resistance pumps in Gram-negative bacteria effectively stop the entry of antimicrobials [8]. On the contrary, Gram-positive bacteria possess a permeable cell wall that usually does not restrict the penetration of biocidal products [8]. In general, plant extracts showed higher antimicrobial activity against Gram-positive compared to Gram-negative bacteria [14, 39-41].

The synergistic effect from the association of antibiotics with phytochemicals against resistant bacteria provides new therapeutic strategies to treat infectious diseases, enabling the use of antibiotics when they are no longer effective by itself during therapeutic treatment. PITC was found to have an additive effect when combined with ERY and CIP in the control of $S$. aureus growth (Table 1). The antimicrobial activity obtained in these situations was significantly higher compared to the antibiotics action alone $(P<0.05)$. This additive effect is most probably due to a double attack of both agents on different target sites of the bacteria. The other combinations produced insignificant antibacterial activities $(P>0.05)$.

The charge properties of the cell surfaces can play a vital role in the microbial homeostasis and resistance to antimicrobial agent [30]. The surface charge of cells is often determined as its zeta potential, which is calculated from the mobility of cells in the presence of an electrical field under well-defined $\mathrm{pH}$ and salt concentrations [42]. The results obtained from the zeta potential measurement (Table 2) shows that $E$. coli and $S$. aureus had a negative surface charge. This happens because of the presence of anionic groups, such as carboxyl and phosphate, in their membrane [30]. The interaction between bacteria and PITC at MIC in-
Table 2. Zeta Potential (mV) Results of Suspensions of $E$. coli and S. aureus in Contact with PITC. The Means \pm SEM for at Least three Replicates are Illustrated

\begin{tabular}{|c|c|c|}
\hline \multirow{4}{*}{ E. coli } & PITC $(\boldsymbol{\mu g} / \mathbf{m L})$ & Zeta potential $(\mathbf{m V})$ \\
\cline { 2 - 3 } & 0 & $-18.4 \pm 0.4$ \\
\cline { 2 - 3 } & MIC & $-15.8 \pm 1.6$ \\
\hline \multirow{3}{*}{ S. aureus } & $5 \times$ MIC & $-16.2 \pm 0.8$ \\
\cline { 2 - 3 } & 0 & $-25.4 \pm 0.6$ \\
\cline { 2 - 3 } & MIC & $-20.5 \pm 0.5$ \\
\hline
\end{tabular}

creased the cell surface charges to less negative values. This effect was significant for both bacteria $(P<0.05)$. The results with PITC at $5 \times$ MIC were found to be similar to those obtained with PITC at MIC $(P>0.05)$.

The cell surface hydrophobicity is defined by the energy of attraction between apolar or slightly polar cells immersed in an aqueous phase. In this study, the cell surface hydrophobicity was determined using the van Oss approach, which allows the assessment of the absolute degree of hydrophobicity of any surface in comparison with their interaction with water. The results demonstrated that cell-PITC interaction causes an alteration of cell surface hydrophobicity (Table $\mathbf{3}$ ). $E$. coli and $S$. aureus cells exhibit hydrophilic properties $\left(\Delta \mathrm{G}^{\mathrm{TOT}}>0 \mathrm{~mJ} / \mathrm{m}^{2}\right)$. The application of PITC promoted the increase of their hydrophilic character $(P<0.05)$, especially for $E$. coli. The phytochemical decreased the apolar component $\left(\gamma^{L W}\right)$ of $S$. aureus surface and the polar $\left(\gamma^{A B}\right)$ component for $S$. aureus and E. coli $(P<0.05)$. The electron donor $\left(\gamma^{-}\right)$ component increased with PITC application for both the bacteria and, therefore, decreased the electron acceptor $\left(\gamma^{+}\right)$ component $(P<0.05)$. This result reports that PITC, as an electrophilic product, significantly interacts with the bacte- 
Table 3. Hydrophobicity ( $\left.\Delta G_{b w b}^{T O T}\right)$, apolar $\left(\gamma^{\mathrm{LW}}\right)$ and polar $\left(\gamma^{\mathrm{AB}}\right)$ Components of the Surface Tension of Untreated and PITC Treated Cells. The Means \pm SEM are Illustrated

\begin{tabular}{|c|c|c|c|c|c|c|}
\hline & \multirow{2}{*}{$\operatorname{PITC}(\mu \mathrm{g} / \mathrm{mL})$} & \multicolumn{4}{|c|}{ Surface Tension Parameters $\left(\mathbf{m} \mathbf{J} / \mathbf{m}^{2}\right)$} & \multirow{2}{*}{$\frac{\text { Hydrophobicity }\left(\mathrm{mJ} / \mathrm{m}^{2}\right)}{\Delta \mathbf{G}_{\mathrm{bwb}}^{\text {TOT }}}$} \\
\hline & & $\gamma^{\mathrm{LW}}$ & $\gamma^{\mathrm{AB}}$ & $\gamma^{+}$ & $\gamma^{-}$ & \\
\hline \multirow{3}{*}{ E. coli } & 0 & $33 \pm 0.7$ & $11 \pm 0.5$ & $2.3 \pm 0.3$ & $52 \pm 0.7$ & $28 \pm 1.3$ \\
\hline & MIC & $26 \pm 1.3$ & $10 \pm 1.0$ & $1.8 \pm 0.4$ & $60 \pm 2.1$ & $40 \pm 0.6$ \\
\hline & $5 \times \mathrm{MIC}$ & $29 \pm 0.8$ & $8.9 \pm 0.7$ & $1.3 \pm 0.6$ & $61 \pm 2.4$ & $42 \pm 0.7$ \\
\hline \multirow{3}{*}{ S. aureus } & 0 & $29 \pm 1.6$ & $11 \pm 0.4$ & $2.5 \pm 0.1$ & $47 \pm 1.1$ & $24 \pm 1.6$ \\
\hline & MIC & $30 \pm 0.9$ & $11 \pm 1.0$ & $2.2 \pm 0.5$ & $53 \pm 2.0$ & $32 \pm 0.9$ \\
\hline & $5 \times \mathrm{MIC}$ & $34 \pm 3.8$ & $7.3 \pm 0.9$ & $1.0 \pm 0.3$ & $55 \pm 0.5$ & $33 \pm 0.4$ \\
\hline
\end{tabular}

rial surface constituents, modifying its physico-chemical properties. PITC is known to react strongly with amino acids, being the reagent for the Edman degradation, a very important reaction for protein sequencing (allows the ordered amino acid composition of a protein to be discovered) [43]. Consequently, the effects promoted by PITC on the bacterial surface properties are arguably related with its ability to react with proteins. Unlike most phytochemicals, in which there is a common sequence of events starting with the interaction of the compound to the cell surface, followed by penetration into the cell and action at the target site; ITCs bind to the external proteins of cell membranes and penetrates to the cell cytoplasm at a lesser extent [15]. Results with cell incubated with PITC at $5 \times$ MIC were very similar $(P>0.05)$ to those obtained with PITC at MIC, suggesting a possible cell surface saturation with PITC at values higher than the MIC.

The Live/Dead BacLight ${ }^{\mathrm{TM}}$ kit determines the membrane integrity by selective stain exclusion [30]. This kit allows the distinction of viable and dead cells: those cells fluorescing green (without membrane damaged) are considered viable cells while the ones fluorescing red (with membrane damaged) are considered dead cells. Representative microscopic visualizations of $E$. coli and $S$. aureus non-exposed to PITC and exposed to PITC at the MIC, for 1 hour, were obtained (data not shown). PITC at MIC and $5 \times$ MIC caused membrane damage of both strains as $100 \%$ of $E$. coli and $S$. aureus cells were PI stained $(P>0.05)$. These results together with those obtained from zeta potential and contact angles assessment demonstrate that PITC interacts with the surface of E. coli and $S$. aureus cells, causing membrane damage and the consequent cell death. Therefore, it is proposed that PITC interacts with cell surface constitutes, especially proteins and other critical biological macromolecules necessary for microbial growth and survival, forming a monolayer around the cell that changes the electrostatic potential and disturbs membrane integrity. This mode of antimicrobial activity suggests the possibility of the concurrent use of PITC with antibiotics in the treatment of drug resistant bacteria. The combination of antimicrobials with a different mode of action from conventional antibiotics may be instrumental in reducing resistance development since the possibility that a pathogen could simultaneously develop resistance against more than one drug is low. For instance, the presence of efflux systems coupled with the narrow porin channels in the outer membrane, which restricts diffusion of antibiotics into the cells, is responsible for the very high intrinsic resistance of Gram-negative bacteria. The antibioticPITC association in antimicrobial chemotherapy may be an interesting strategy to circumvent the antibiotic efflux and enzyme inactivation resistance mechanisms.

\section{CONCLUSION}

The results from this study showed that PITC had significant antimicrobial activity on the tested bacteria, particularly on E. coli. PITC also showed a good efficacy against $S$. aureus strains when combined with CIP and ERY due to an additive effect. PITC was found to interact strongly with bacterial surfaces (independent from the Gram type), resulting in cell death. When incubated with PITC, the bacterial surface became less negative and more hydrophilic. The reaction of PITC with proteins at the membrane may be the cause of the changes on surface properties. Despite PITC seems to be a promising product for antimicrobial therapy against the tested bacteria, the conflicting pro- and antioxidative and toxicity effects of ITCs still require careful management of these compounds in human use. It is mandatory to test the toxicity effect of PITC before considering it for clinical applications. However, immediate practical applications can be proposed for antiseptic and disinfectant formulations. Indeed, isothiocyanates are known to be readily inactivated in the environment and are readily and cheaply synthesized hence they represent potentially acceptable disinfectants.

\section{CONFLICT OF INTEREST}

The author(s) confirm that this article content has no conflicts of interest.

\section{ACKNOWLEDGEMENTS}

This work was supported by Operational Programme for Competitiveness Factors - COMPETE and by FCT - Portuguese Foundation for Science and Technology through Projects Bioresist - PTDC/EBB-EBI/105085/2008; Phytodisinfectants - PTDC/DTP-SAP/1078/2012; the PhD grant (SFRH/BD/63398/2009-Anabela Borges) and the PostDoctoral grant (SFRH/BPD/81982/2011-Lúcia C. Simões). 


\section{REFERENCES}

[1] Alanis, A.J. Resistance to antibiotics: are we in the post-antibiotic era? Arch. Med. Res. 2005, 36, 697-705.

[2] Aminov, R.I. The role of antibiotics and antibiotic resistance in nature. Environ. Microbiol. 2009, 11, 2970-2988.

[3] Coutinho, H.; Costa, J.; Lima, E.; Falcao-Silva, V.; Siqueira, J. Herbal therapy associated with antibiotic therapy: potentiation of the antibiotic activity against methicillin - resistant Staphylococcus aureus by Turnera ulmifolia L. BMC Complem. Altern. M. 2009, 9, $1-4$.

[4] Nascimento, G.G.; Locatelli, J.; Freitas, P.C.; Silva, G.L. Antibacterial activity of plant extracts and phytochemicals on antibiotic-resistant bacteria. Braz. J. Microbiol. 2000, 31, 247-256.

[5] Brehm-Stecher, B.F.; Johnson, E.A. Sensitization of Staphylococcus aureus and Escherichia coli to antibiotics by the sesquiterpenoids nerolidol, farnesol, bisabolol, and apritone. Antimicrob. Agents Chemother. 2003, 47, 3357-3360.

[6] Gould, I.M. A review of the role of antibiotic policies in the control of antibiotic resistance. J. Antimicrob. Chemother. 1999, 43, 459465.

[7] Cowan, M.M. Plant products as antimicrobial agents. Clin. Microbiol. Rev. 1999, 12, 564-582.

[8] Simões, M.; Rocha, R.; Coimbra, M.A.; Vieira, M. Enhancement of Escherichia coli and Staphylococcus aureus antibiotic susceptibility using sesquiterpenoids. Med. Chem. 2008, 4, 616623.

[9] Phillipson, J.D. Phytochemistry and medicinal plants. Phytochemistry. 2001, 56, 237-243.

[10] Osbourn, A.E. Preformed antimicrobial compounds and plant defense against fungal attack. Plant Cell. 1996, 8, 1821-1831.

[11] Newman, D.J.; Cragg, G.M.; Snader, K.M. The influence of natural products upon drug discovery. Nat. Prod. Rep. 2000, 17, 215-234.

[12] Jayaraman, P.; Sakharkar, M.K.; Lim, C.S.; Tang, T.H.; Sakharkar, K.R. Activity and interactions of antibiotic and phytochemical combinations against Pseudomonas aeruginosa in vitro. Int. J. Biol. Sci. 2010, 6, 556-68.

[13] Rodman, J.E.; Karol, K.G.; Price, R.A.; Sytsma, K.J. Molecules, morphology, and Dahlgren's expanded order Capparales. Syst. Bot. 1996, 21, 289-307.

[14] Aires, A.; Mota, V.R.; Saavedra, M.J.; Rosa, E.A.S.; Bennett, R.N. The antimicrobial effects of glucosinolates and their respective enzymatic hydrolysis products on bacteria isolated from the human intestinal tract. J. Appl. Microbiol. 2009, 106, 2086-2095.

[15] Gomes de Saravia, S.G.; Gaylarde, C.C. The antimicrobial activity of an aqueous extract of Brassica negra. Int. Biodeter. Biodegr. 1998, 41, 145-148.

[16] Fahey, J.W.; Zalcmann, A.T.; Talalay, P. The chemical diversity and distribution of glucosinolates and isothiocyanates among plants. Phytochemistry. 2001, 56, 5-51.

[17] Sarwar, M.; Kirkegaard, J.A.; Wong, P.T.W.; Desmarchelier, J.M. Biofumigation potential of brassicas. Plant Soil. 1998, 201, 103112 .

[18] Bending, G.D.; Lincoln, S.D. Inhibition of soil nitrifying bacteria communities and their activities by glucosinolate hydrolysis products. Soil Biol. Biochem. 2000, 32, 1261-1269.

[19] Jacob, C. A scent of therapy: pharmacological implications of natural products containing redox-active sulfur atoms. Nat. Prod. Rep. 2007, 38, 851-863.

[20] Saavedra, M.J.; Borges, A.; Dias, C.; Aires, A.; Bennett, R.N.; Rosa, E.S.; Simões, M. Antimicrobial activity of phenolics and glucosinolate hydrolysis products and their synergy with streptomycin against pathogenic bacteria. Med. Chem. 2010, 6, 174-83.

[21] Morra, M.J.; Kirkegaard, J.A. Isothiocyanate release from soilincorporated Brassica tissues. Soil Biol. Biochem. 2002, 34, 16831690 .

[22] Norsworthy, J.K.; Meehan, J.T. Use of isothiocyanates for suppression of Palmer amaranth (Amaranthus palmeri), pitted morningglory (Ipomoea lacunosa), and yellow nutsedge (Cyperus esculentus). Weed Sci. 2005, 53, 884-890.
[23] Zhang, Y.; Yao, S.; Li, J. Vegetable-derived isothiocyanates: antiproliferative activity and mechanism of action. P. Nutr. Soc. 2006, 65, 68-75.

[24] Borek, V.; Elberson, L.R.; McCaffrey, J.P.; Morra, M.J. Toxicity of aliphatic and aromatic isothiocyanates to eggs of the black vine weevil (Coleoptera: Curculionidae). J. Econ. Entomol. 1995, 88, 1192-1196.

[25] Clinical and Laboratory Standards Institute (CLSI)/NCCLS. Performance standards for antimicrobial susceptibility testing; Approved Standard-Eighth Edition. CLSI/NCCLS document M2A8. West Valley Road, Pennsylvania, USA, 2007.

[26] Bauer, A.W.; Kirby, W.M.; Sherris, J.C.; Turck, M. Antibiotic susceptibility testing by a standardized single disk method. Am. $J$. Clin. Pathol. 1966, 45, 493-496.

[27] Holst, B.; Williamson, G. A critical review of the bioavailability of glucosinolates and related compounds. Nat. Prod. Rep. 2004, 21, 425-447.

[28] Aires, A.; Mota, V.R.; Saavedra, M.J.; Monteiro, A.A.; Simões, M.; Rosa, E.A.S.; Bennett, R.N. Initial in vitro evaluations of the antibacterial activities of glucosinolate enzymatic hydrolysis products against plant pathogenic bacteria. J. Appl. Microbiol. 2009, 106, 2096-2105.

[29] Simões, L.C; Simões, M.; Vieira, M. Adhesion and biofilm formation on polystyrene by drinking water-isolated bacteria. Anton. Leeuw. Int. J. G. 2010, 98, 317-329.

[30] Ferreira, C.; Pereira, A.M.; Pereira, M.C.; Melo, L.F.; Simões, M. Physiological changes induced by the quaternary ammonium compound benzyldimethyldodecylammonium chloride on Pseudomonas fluorescens. J. Antimicrob. Chemother. 2011, 66, 18.

[31] Busscher, H.J.; Weerkamp, A.H.; van der Mei, H.C.; van Pelt, A.W.; de Jong, H.P.; Arends, J. Measurement of the surface free energy of bacterial cell surfaces and its relevance for adhesion. Appl. Environ. Microb. 1984, 48, 980-983.

[32] van Oss, C.J.; Chaudhury, M.K.; Good, R.J. Monopolar surfaces. Adv. Colloid. Interf. Sci. 1987, 28, 35-64.

[33] van Oss, C.J.; Good, R.J.; Chaudhury, M.K. Additive and nonadditive surface tension components and the interpretation of contact angles. Langmuir. 1988, 4, 884-891.

[34] van Oss, C.J.; Ju, L.; Chaudhury, M.K.; Good, R.J. Estimation of the polar parameters of the surface tension of liquids by contact angle measurements on gels. J. Colloid. Interf. Sci. 1989, 128, 313319.

[35] Janczuk, B.; Chibowski, E.; Bruque, J.M.; Kerkeb, M.L.; Caballero, F.G. On the consistency of surface free energy components as calculated from contact angles of different liquids: an application to the cholesterol surface. J. Colloid Interf. Sci. 1993, 159, 421-428.

[36] Berney, M.; Hammes, F.; Bosshard, F.; Weilenmann, H.-U.; Egli, $\mathrm{T}$. Assessment and interpretation of bacterial viability by using the Live/Dead BacLight Kit in combination with flow cytometry. Appl. Environ. Microb. 2007, 73, 3283-3290.

[37] Dangl, J.L.; Jones, J.D.G. Plant pathogens and integrated defence responses to infection. Nature 2001, 411, 826-833.

[38] Tegos, G.; Stermitz, F.R.; Lomovskaya, O.; Lewis, K. Multidrug pump inhibitors uncover remarkable activity of plant antimicrobials. Antimicrob. Agents Chemother. 2002, 46, 31333141.

[39] Delaquis, P.J.; Stanich, K.; Girard, B.; Mazza, G. Antimicrobial activity of individual and mixed fractions of dill, cilantro, coriander and eucalyptus essential oils. Int. J. Food Microbiol. 2002, 74, 101109.

[40] Alzoreky, N.S.; Nakahara, K. Antibacterial activity of extracts from some edible plants commonly consumed in Asia. Int. J. Food Microbiol. 2003, 80, 223-230.

[41] Duraipandiyan, V.; Ayyanar, M.; Ignacimuthu, S. Antimicrobial activity of some ethnomedicinal plants used by Paliyar tribe from Tamil Nadu, India. BMC Compl. Alt. Med. 2006, 6, 35 .

[42] Palmer, J.; Flint, S.; Brooks, J. Bacterial cell attachment, the beginning of a biofilm. J. Ind. Microbiol. Biot. 2007, 34, 577-588.

[43] Steen, H.; Mann, M. The abc's (and xyz's) of peptide sequencing. Nat. Rev. Mol. Cell Bio. 2004, 5, 699-711. 